\title{
Ensuring the credibility of thickening technology
}

\author{
R.J. Jewell Australian Centre for Geomechanics, Australia
}

\begin{abstract}
Advances in thickening technology over recent years have made possible the production of tailings at underflow densities that were previously unattainable. The potential in terms of increased water recovery within the plant and TSF storage efficiency in above ground storages is a major factor in the increasing interest by mine operators in adopting the technology in new operations as well as retrofitting existing operations. There are a number of practical issues related to being able to consistently achieve design underflow densities from the new generation of thickeners in particular. There is also evidence that in a number of cases the predictions of beach slopes for high yield stress tailings may be overly optimistic when compared with field observations. The extra costs involved in thickening tailings must be balanced against the benefits to be gained from the technology and it is necessary to ensure that the designed product can be produced consistently. The downside of not meeting design targets could significantly affect the credibility of the technology and delay ongoing implementation.
\end{abstract}

\section{Introduction}

The Kidd Creek Mine in Ontario is credited as being the first application of additional thickening of tailings before discharge for above ground disposal. Eli Robinsky (1999) proposed the concept for Kidd Creek to overcome the undesirable environmental impact of conventional tailings deposits and extremely expensive confining dams associated with earlier conventional tailings deposits in that part of Ontario. The concept was to remove much of the excess process water from the tailings prior to discharge such that a heavy but pumpable slurry possessing high viscosity or high internal friction would be created. Such a slurry could be expected to stack to a gentle self supporting slope forming a cone around a central discharge point such that the perimeter dam height could be reduced for a given storage capacity and the settling (decant) pond eliminated altogether. A major challenge encountered in the early 1970s when the Kidd Creek operation was set up, was achieving an underflow density sufficiently high to create the required beach slopes using the conventional thickeners then available.

As Robinsky wrote in the preface to the second edition of the Paste and Thickened Tailings (P\&TT) guide (Jewell and Fourie, 2006)

"in those days thickeners were designed to clarify water - not to produce a heavy underflow.

Rakes could not sustain the necessary torque to move the heavy slurry, and the shallow thickener depth did not provide the deep bed necessary for self-weight consolidation. The use of flocculants was just beginning to be exploited and the cost of filters and centrifuges to permit the adoption of TTD was just too prohibitive".

Since then, the art of thickening tailings has advanced rapidly with new and evolving thickener types and designs and flocculants to the extent that very high density slurries and indeed paste can now be produced as underflow from tank thickeners.

An important parameter required for the estimation of the design capacity of a TSF for stacked thickened tailings is the beach slope. The original work undertaken by Robinsky predicted beach slopes corresponding to slopes measured in laboratory based flume tests. However, from observations of full scale mining operations it is clear that the slopes predicted from small laboratory flume tests are not valid as slope prediction tools. Unfortunately, there is still no generally recognised approach to the accurate prediction of beach slope angles and this remains an area in which there is considerable potential for over optimistic design predictions.

The reasons for adopting the thickened tailings concept for any given site will vary according to the needs of the operation, but in all cases the outcomes promised must accrue to justify the additional costs incurred in 
thickening and transporting the tailings. Experience has shown that there are a number of practical operating issues that result in fluctuations in the consistency of the thickener underflow and this can significantly affect the prospect of achieving the predicted outcome on a consistent basis. This paper has been prepared to highlight some of these issues and their consequences in order to alert service providers to the danger of adopting optimistic design parameters and overselling the concept and potential users to the influence their own operating practices have in achieving the design outcomes. At risk are the credibility of the technology and the danger of alienating the mining industry through cost over-runs and failure to achieve design outcomes at a time when the operators of the very large throughput mines in Chile and elsewhere are commissioning studies to examine the possibility of adopting the thickened tailings concept.

\section{Basis of concern}

A number of recent cases in which the design parameters adopted appear to be overly optimistic have led to the decision to prepare this paper. To provide more than just thoughts and ideas, some of the details of one operation which the author reviewed are presented as an example. The issues presented here for review have been limited to the design consistency of the underflow from very large diameter deep cone thickeners; expectations regarding the requirements for the management of the thickeners and the predicted beach slopes.

The plant was to consist of two banks of very large diameter deep cone thickeners, each with a throughput of the order of 12 to 15 thousand tonnes per day. The underflow density and throughput of the thickeners were designed on the basis of static sedimentation tests and bench top dynamic thickening tests on samples of ore from the mine as outlined in the following section. The thickeners were to be fully instrumented and the expectation seemed to be that they would operate automatically under the supervision of one operator for each bank of 10 thickeners. The thickeners were to be established at an elevation such that the tailings were expected to be discharged primarily under gravity with limited shear thinning and to spread out across the TSF at beach slopes of somewhere between 5 and $8 \%$.

\subsection{Design consistency}

To confirm the laboratory based design of the tailings consistency from the thickener underflow, pilot scale testing was carried out on site using approximately $1 \mathrm{~m}$ diameter deep cone thickeners. During the review process, reports from site indicated that the underflow densities being achieved were considerably less (up to say 5\%) than predicted. Site personnel then advised that there was considerable variation in the rheology of the orebody across the site and that the plant operators recognised three broad categories of ore on the basis of the difficulty of extracting the mineral. The ore being processed during (and supplied to) the pilot studies contained considerably more clay than the other categories and was labelled as 'difficult' and was obviously different from the sample(s) provided for the laboratory testing. To operate the plant under these conditions meant that those responsible for operating the full scale thickeners would need advance warning of any change in feed ore and for the transport and discharge systems to be designed to take account of the different thickener underflow consistencies.

\subsection{Operating challenges}

As will be discussed in the following sections there are a number of reasons why the use of tailings thickeners should not be thought of in terms of a 'set and forget' operation. Deep cone thickeners operate in a range of consistency in which very small changes in solids content can induce a large change in yield shear stress. The sensitivity and reliability of current thickener instrumentation do not currently provide the predictive certainty to enable completely automated operations and the variability in feed ore as discussed above further complicates the situation. As an illustration of the challenges that can be involved in operating a deep cone thickener, Figure 1 is a photograph of a placard on the wall of the control room of the $15 \mathrm{~m}$ diameter deep cone thickener installed at Kimberly in South Africa for EKAPA. The photograph was taken during a site visit in 2004 when the plant was relatively new and the operators were coming to terms with the thickener. The notice illustrates the challenges and frustrations that could be faced in operating these thickeners and although the paper presented during Paste04 by Holmes et al. (2004) suggested that a number of modifications to the plant over time "made the operation of the plant much smoother and nearly operator 
free", the site visit followed the presentation of the paper and the consistency of the tailings being discharged into the pit was noticeably variable during our visit.

\section{WARNING!}

This plant is very sensitive and does not function to specification during visits by VIP's or those who are not personnel of the company.

A special circuit in the machine called a 'critical detector' senses visitors and the manager's emotional state in terms of how desperate he or she is that the plant should operate perfectly. Symptoms may include:

1) Failure to flocculate

2) Impressive overflow of the Return Water Tank usually in the form of mud rather than clear water.

3) Blockage of the underflow pipes and pumps, the opening of which results in $150 \mathrm{~mm}$ of slippery mud over entire concrete pad.

4) Prolific leakage from flanges, usually under pressure, due to failure of valves in pumps.

These symptoms commonly result in soaked labourers and muddy and panicking managerial staff.

Praise the plant prolifically, even if the Return water is running at $5000 \mathrm{ppm}$ or higher. Praise the cleanliness of the surroundings. Do not ask any awkward questions.

\section{Figure 1 The placard at the EKAPA deep cone thickener}

\subsection{Beach slope prediction}

The designed elevation of the thickeners and the extent of the spread of the tailings had been based upon predictions that the beach slopes would develop somewhere over a range of between 5 and $8 \%$. There was no way in which these predictions could be challenged, except to note that beach slopes of that magnitude had not been developed on a continuous basis or at that rate of throughput at any operation involving deep cone thickeners anywhere in the world at that time. On the basis of experience at thickened tailings operations, as can be seen from a list of projects around the world presented by Williams et al. (2008), it appeared to be more prudent to consider a range of beach slopes of between say 2 and $5 \%$ for the design process.

For the Miduk copper project in Iran the design prediction for supergene as listed by Williams et al. (2006) was $3.5 \%$ and it was expected that the underflow percent solids and beach angle would increase slightly as the change to hypogene ore occurred. The 2006 paper indicates that the beach slopes measured during a survey in August 2005 were around 2.3-2.4\% and the beach slope listed in the 2008 paper for the project was $2.5 \%$. ATC Williams has been involved with more surface disposal schemes involving thickened tailings than any other consultant in the world and for them to over-predict the beach slope at Miduk indicates that beach slope angles developed in the field will more often than not be less than predicted.

Steeper beach slopes might have eventually developed on the project under discussion here, but the variability of the feed ore and the inherent conservatism in the operation of thickeners as will be discussed later together with the experience from Miduk suggest that a beach slope of around 2.5-3\% would be a realistic value to expect and that the range of between 2 and $5 \%$ would be rational for design. It is possible that not achieving the predicted underflow densities or beach slopes may not have been 'show stoppers' in the viability of the proposed system, but they would have required modifications to the system during operations that would have involved significant additional costs and dented the faith of mine operators in the concept.

\section{The thickening process}

The process of thickening tailings can be described as a continuum covering a range of solids content from very low density slurry through to a cake-like consistency as water is removed and the particles pack closer 
together. Figure 2 provides data presenting the resulting increase in yield stress of tailings as the density increases for a range of mine waste streams. Different types of ore within individual mines can also exhibit different properties, although not with the extreme range of values shown in this figure. In Chapter 1 in the P\&TT guide (Jewell and Fourie, 2006), a yield stress range of the order of say $200+/-25 \mathrm{~Pa}$ (at the point of discharge) is proposed as marking the transition between slurry and paste. For high density slurries and paste, the yield stress increases rapidly with solids content and is sensitive to relatively small changes in the water content. Producing a consistent high yield stress underflow for any given ore involves operating the thickener within a narrow band of water content and this creates operational challenges. The water content, underflow density and solids content (solids mass fraction) are interrelated terms representing the consistency of the tailings and for convenience have been used interchangeably throughout this paper.

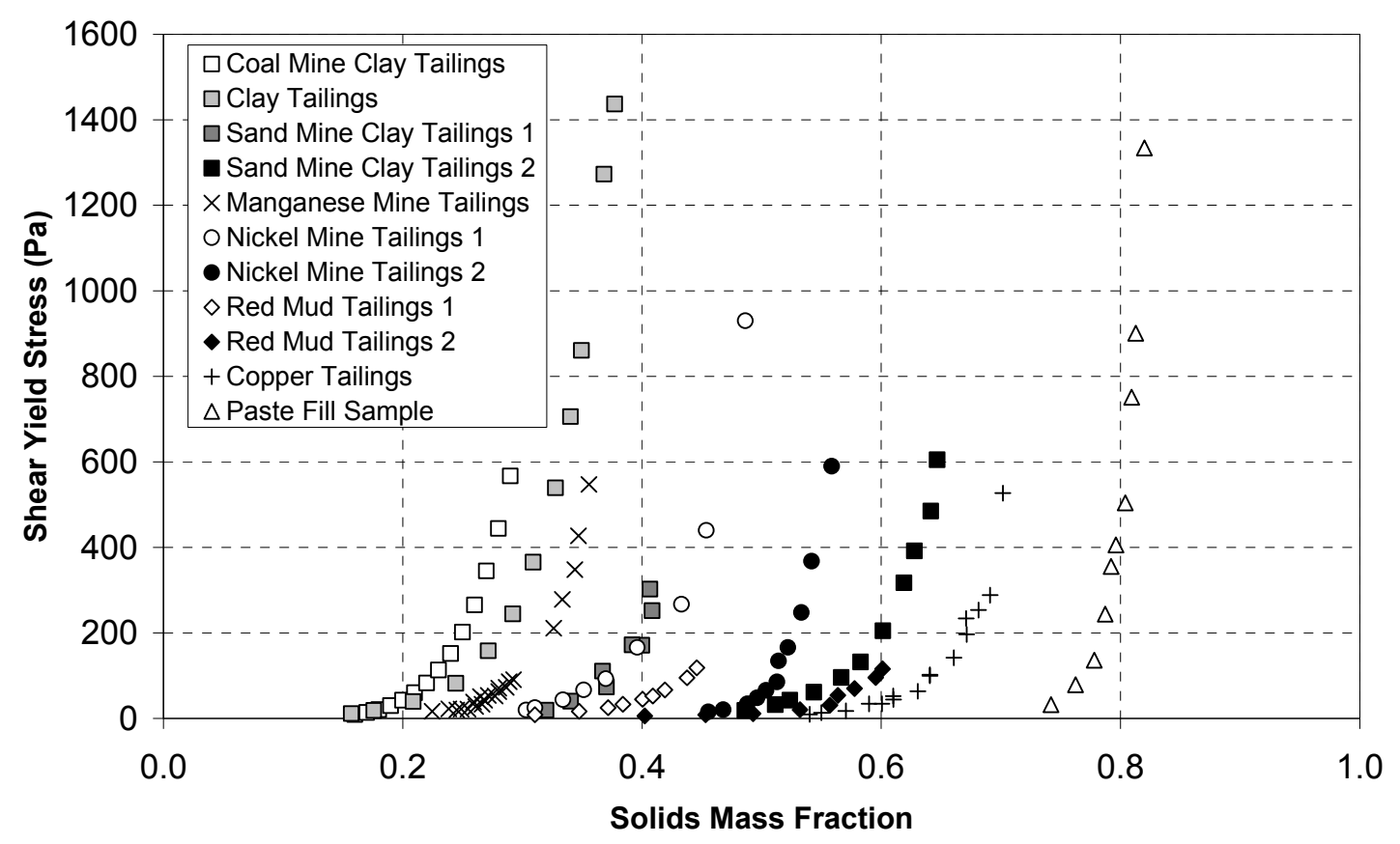

Figure 2 Yield stress concentration data for different industry waste streams (Jewell and Fourie, 2006)

During the design stage for any project, testing of samples from the orebody is undertaken by the thickener manufacturers to establish the size of the thickeners and process conditions to meet the objectives set by the mine owners in terms of degree of thickening and the requirements of the tailings storage facility (TSF). For example:

- Static sedimentation tests are undertaken in order to perform a basic thickener sizing exercise. These determine the optimum process conditions for flocculation within a thickener such as feed solids concentration; flocculant type; flocculant dose; settling rate and underflow solids concentration.

- Bench top dynamic thickening tests are needed for the plant design and costing to determine the optimum thickening area required for a specific process condition $(\mathrm{t} / \mathrm{h})$. The data generated are required to adequately size the diameter and number of the thickeners required by the process.

- In most situations in which the objective is to thicken tailings to the maximum practical using the sedimentation process and short of reverting to the use of filters, further testing is undertaken on site using pilot plants which model the deep cone thickeners (DCT) used in that situation. This is particularly important on large operations with large throughput. In these situations very large ore bodies are usually involved and it is important to ensure that the range of samples tested covers the different types of ore where there may be significant variations in the properties of the orebody across the mine. 
The usual expectation is that the plant designed on the basis of this process will then be operated to produce the underflow solids concentration as established by the design continuously from start-up. However, in practice there will almost certainly be variations in the consistency of the underflow - some of short duration and some for longer periods. The consequences of that variation will be different depending upon the degree of thickening and whether the solids content and hence yield shear stress is higher or lower than the design value. When the product is designed to have a relatively low yield stress, the implications of fluctuations in the solids content of the underflow are generally not significant either way as long as the material can be removed from the thickener and transported to the TSF. However, with thickeners designed to produce a very high density slurry or paste, even minor variations in solids content can have a significant effect on the yield stress and hence also the transport and disposal of the product. There is also the potential to have an effect on the beach slope angles that can be generated with the deposited tailings when the yield stress is less than designed and importantly on the stability of the deposit when the yield stress of the tailings varies for any length of time during the life of the deposit.

\section{$4 \quad$ Operating challenges for thickeners}

The underflow density that can be obtained from any given thickener is a function of a number of factors including the properties of the ore and the design features of the thickener. The features that enable modern thickeners to produce a high density underflow include an effective feedwell system capable of effectively seeding the flocculant, a deep bed for settling and consolidating tailings and a mechanism for releasing water freed from the settling tailings and to rake the dense tailings at the base of the column to the underflow outlet. A comprehensive review of the range of thickeners and filters available and of their operation may be found in Chapter 7 of the P\&TT guide (Jewell and Fourie, 2006).

There are very few operations in which the level of instrumentation available to monitor and regulate bed depth and other important parameters is believed to be sufficient to enable these thickeners to be fully automated and in general operators possessing considerable skill and experience are still required to control these installations manually. This introduces a human judgement factor which adds to the variables affecting the performance of thickeners designed to produce high density underflows as are discussed below. Variable ore types.

The mineralogy and hence rheology of the tailings after extraction of the valuable minerals has a major influence on the thickening process. Sedimentation and consolidation are gravity driven processes and as can be seen in Figure 2, clay minerals settle to a considerably lower density than granular shaped particles and this remains so even when reduced to $-2 \mu \mathrm{m}$ sizes by the comminution process. Where the orebody is not homogeneous, the design process has to take the degree of variability into account. For example, where it is possible to mix different ores prior to processing to provide a continuously uniform feed, the plant design can be based on a representative sample. Alternatively, where the different ore types will be mined and processed at different times, the plant, transport system and TSF have to be designed to handle the range of consistency of the tailings produced.

\subsection{Operator issues}

The influence of the operators is evident in the start-up period when the plant is being commissioned, but probably more importantly during ongoing operations. During start-up, the plant underflow that feeds the thickeners takes time to thicken up to the design consistency and the density of the thickener underflow is correspondingly low. Even when the feed density reaches the design consistency, the operators have to experiment to optimise the flocculant dosage and to establish the required bed depth in the thickeners to achieve the underflow design density. The net effect is that the thickener underflow density is often considerably below the design value during this period and as a result, the tailings may not achieve the desired yield stress or beach slopes when discharged into the TSF. Experience has shown that in some instances this start-up period can last for considerable periods until the desired equilibrium conditions are established.

Encouraging plant operators to achieve the underflow density established during the design process on a continuous basis has also been shown by experience to be a challenge. Regardless of whether the thickener is a high rate thickener (HRT), a DCT or somewhere in between, the greatest fear for operators appears to be 
for the tailings to consolidate more than anticipated and to resist efforts to be directed towards and out of the underflow outlet. This can result in the raking system breaking down and/or bogging of the thickener. In all instances, the thickener becomes inoperable and expensive labour-intensive remedial measures have to take place. Regardless of whether for example the cause is a lack of faith in the instrumentation measuring bed depth or rake torque or experience with unanticipated changes in the mineralogy of the feed ore, the operators tend to play safe and in many operations the consistency of the underflow tailings is regularly lower than the design value.

The flocculant type and dosage is initially determined during the design process as described in Section 3 above. For any number of reasons, this dosage will be varied during operations as the operators try to counter issues such as changing ore type. Experience has shown that in many operations this results in considerably higher flocculant dosages (and expense for the operation) than originally designed and in many cases higher than needed.

\section{Outcomes}

The design of the operation downstream of the thickener including the transport system and the dimensions of the TSF itself will have been matched to the properties of the tailings expected from the thickener underflow. As can be seen from numerous papers published in the proceedings from the P\&TT seminars conducted annually under the auspices of the ACG, the components of the pumping and pipeline systems designed to transport the thickened tailings to the TSF are evolving apace with the thickening techniques and equipment. The yield shear stress of the tailings is a major input parameter into pump and pipeline design and variations from the design value can have a significant effect on the performance of the system designed. In addition, as an evolving technology, there is potential for over or under design of the equipment and when combined, these issues have the potential to involve cost penalties for mining projects. However, issues related to tailings transport deserve a full dissertation on their own and this aspect of the thickened tailings technology will not be discussed further in this paper.

With conventional low density tailings slurries, the capacity of any TSF is limited to what can be stored below the safe water level. When the tailings are thickened and discharged as higher density slurries there is less (or no) supernatant water released on discharge, the tailings do not segregate and the tailings can beach at steeper angles. The combination of a reduced need to retain and store free water on the TSF and stable higher density stacked tailings can result in significant increases in the storage capacity on any given footprint, or alternatively reduced heights of confining embankments for any given mass of tailings.

\subsection{Beach slope predictions}

The most critical parameter required for the design capacity of a TSF for stacked thickened tailings is the beach slope. Considerable advances have been made recently in understanding the mechanism of formation of tailings beaches as for example is outlined by Williams et al. (2008). Unfortunately, there is still no generally recognised approach to the accurate prediction of beach slope angles and this remains an area in which there is considerable potential for over optimistic and unsustainable predictions.

The original work undertaken by Robinsky predicted beach slopes corresponding to slopes measured in laboratory based flume tests. However, from observations of full scale mining operations it is clear that the slopes predicted from small laboratory flume tests are not valid as slope prediction tools. Current studies such as those described by Williams et al. (2008) and the approach outlined by Luppnow et al. (2009) show examples of the empirical modelling being undertaken by different consultants in the absence of a rational design method. Before any approach can be accepted it will be necessary for a number of studies involving significant operations in which rational predictions of beach slope can be compared with subsequent field performance and to date there is no evidence that any such correlations have been undertaken.

One semi-rational approach currently being evaluated using an entropy-stream power approach as described by McPhail (2008) is based upon rheological and small scale trial deposition data. Predictions have recently been made for a project that may provide a correlation between the prediction and performance in the field in the event that the mine is eventually developed. There are, however, a large number of factors involved in the approach proposed by McPhail and even minor differences may require additional trials that could render a comprehensive evaluation of the approach very tedious. 
What appears to be evident at this stage is that regardless of how they have been derived, all beach slope predictions should be compared with data obtained by observation of the thickened tailings operations around the world. Where established operations exist, the data from those operations should give some indicator to the beach slopes that could develop at a proposed operation with similar tailings and in a similar environment. Williams et al. (2008) have included a list of projects world-wide that facilitates such a comparison. In essence, these data suggest that high clay content tailings such as red mud from bauxite plants rarely exceed slopes of $1 \%$ and more granular tailings derived from hard rock ores rarely produce slopes exceeding around $2.5 \%$. Steeper slopes can be developed with filtered tailings such as at Bulyanhulu as described by Shuttleworth et al. (2005) and listed by Williams et al. (2008) and with tailings produced from some ores with favourable rheology such as at the Osborne Mine in Queensland as described by McPhail (2007). However, at Osborne the beach slopes flattened considerably when the mineralogy of the feed ore changed.

Where data do not appear to be available from conforming operations, the design has to be derived on the basis of a full suite of rheological, geotechnical and environmental parameters tempered by the best available advice based upon experience. This experience will almost certainly be derived from existing operations.

\section{Consequences}

The principal reasons for adopting the thickened tailings concept would be to minimise the volume of makeup water required per tonne of ore involved in the process; to increase the storage capacity and stability of the TSF and to reduce the potential for damage to the environment from seepage from the base of the TSF or through the confining embankments.

In the event that the density of tailings from the thickener underflow is greater than designed, the outcome for all of these drivers would be positive and if there are any concerns they would relate to getting the tailings out of the thickener and the ability of the transport and disposal systems to cope with the increased consistency and yield stress of the tailings. Alternatively, when the design consistency of the thickener underflow is not achieved, even if for only part of the time, the design outcomes for the system are likely to be compromised to some extent. This may be more readily discussed with the aid of Figure 3 below:

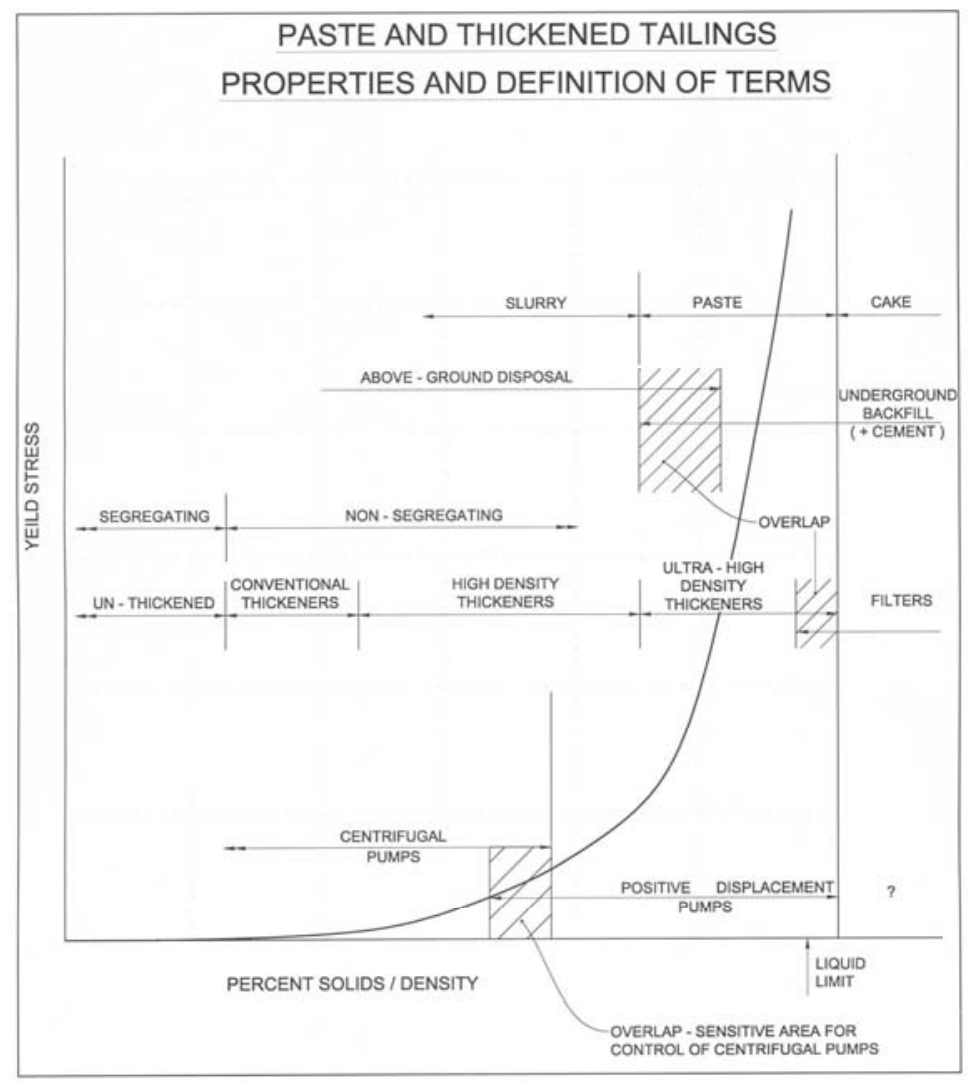

Figure 3 Properties of the thickened tailings continuum (Jewell and Fourie, 2006) 
An examination of Figures 2 and 3 will suggest that the difficulty in extracting process water from tailings will increase as the consistency increases towards a paste. This suggests that while the maximum water return will be gained by using filters, the most economic return will be gained from thickeners such as high rate thickeners which have lower installation and operating costs than filters and the ultra-high density (paste) thickeners. This suggests that if the sole driver is water saving, the use of filters and ultra-high density (paste) thickeners would be difficult to justify and that when they are installed on a project, a small drop in yield stress will not be of great importance to the volume of water returned to the plant.

The storage capacity of a TSF with a given footprint is principally a function of the density of the tailings and the beach slopes that can be achieved. Thickening tailings has the effect of reducing the size of the void spaces between the particles and hence the volume of excess water contained and increasing the difficulty in extracting the remaining water from the voids. Any excess water may be removed on deposition from lower density tailings as supernatant water, but beyond that the principal mechanisms for the removal of water are self weight consolidation and evaporation. The higher the degree of thickening, the higher the initial density of the deposited tailings and self weight consolidation will result in higher final densities for the deposit as a whole. Water driven from the tailings by consolidation will either rise to the surface and evaporated or report to the base or perimeter embankments as seepage. The higher the degree of thickening, the less potential there will be for the need for a free water 'decant' pond located on the TSF and the beach slope can be oriented to direct rainfall runoff to a separate rainfall collection area.

With the ultra-high density (paste) thickeners now available, the expectation is that the high yield stresses being produced will result in higher final densities and steeper beach slopes than those observed to date. However, until steeper beaches can be shown to be produced on a consistent basis over the life of a high throughput mine, designers need to be cautious of promoting claims of being able to achieve such outcomes. A $1 \%$ reduction in beach slopes can have very significant influence in the ultimate storage capacity of any given TSF or on the spread of tailings from a fixed discharge point and a reduction of that order can result from relatively modest reductions in the yield stress of discharged tailings.

Tailings produced at a lower consistency than designed during start-up, or intermittently for any reason for periods during the life of a mine could also be expected to have a significant effect on the ultimate stability of a tailings deposit. During start-up, the geometry of the TSF often results in the formation of thick lifts of tailings that then become thinner as the beach area increases. Where these thick lifts are of lower strength, the deposit is being constructed upon a weakness at the base that could for example be mobilised by seismic activity or even more simply in time by the mass of the tailings placed above. Similarly, a layer of lower strength tailings sandwiched between stronger layers as a result of the processing of a lower strength ore for any period could form the mechanism for a failure under adverse conditions.

\section{Conclusions}

Advances in thickening technology over recent years have made possible the production of tailings at underflow densities that were previously unattainable. The potential in terms of increased water recovery within the plant and TSF storage efficiency in above ground storages is a major factor in the increasing interest by mine operators in adopting the technology in new operations as well as retrofitting existing operations. There are a number of practical issues related to being able to consistently achieve design underflow densities from the new generation of thickeners in particular that have been discussed in this paper. There is also evidence that in a number of cases the predictions of beach slopes for high yield stress tailings may be overly optimistic when compared with field observations. This paper has been prepared to highlight some of these issues and their consequences in order to alert service providers to the danger of adopting optimistic design parameters and overselling the concept, and potential users to the influence their own operating practices can have in achieving the design outcomes.

The extra costs involved in thickening tailings must be balanced against the benefits to be gained from the technology and to achieve the benefits it is necessary to ensure that the designed product can be produced safely and consistently. At risk are the credibility of the technology and the danger of alienating the mining industry through cost over-runs and failure to achieve design outcomes. 


\section{References}

Hohne, J., Bedell, D. and Fogwell, G. (2004) Ekapa Mining Success Story using the Dorr-Oliver Eimco Deep Cone Paste Thickener, In Proceedings of the International Seminar on Paste and Thickened Tailings, Paste 2004, Paper $14,16 \mathrm{p}$.

Jewell, R.J. and Fourie, A.B. (2006) Paste and Thickened Tailings - A Guide, Second Edition, Australian Centre for Geomechanics, Perth, Australia, 255 p.

Luppnow, D., Moreno, J. and Palape, M. (2009) Control and Management of Thickened Tailings Beach - A Simplified Approach, In Proceedings Twelfth International Seminar on Paste and Thickened Tailings, Australian Centre for Geomechanics, Perth, Australia, pp. 245-269.

McPhail, G.I. (2007) Osborne High Density Discharge - An Update from 2004, In Proceedings Tenth International Seminar on Paste and Thickened Tailings, Australian Centre for Geomechanics, Perth, Australia, pp. 339-350.

McPhail, G.I. (2008) Prediction of the Beach Profile of High-Density Thickened Tailings from Rheological and SmallScale Trial Deposition Data, In Proceedings Eleventh International Seminar on Paste and Thickened Tailings, Australian Centre for Geomechanics, Perth, Australia, pp. 179-188.

Robinsky, E.I. (1999) Thickened Tailings Disposal in the Mining Industry, E.I. Robinsky Associates Limited, Canada.

Shuttleworth, J.A., Thompson, B.J. and Wates, J.A. (2005) Surface Paste Disposal at Bulyanhulu Practical Lessons Learned, In Proceedings International Seminar on Paste and Thickened Tailings, Australian Centre for Geomechanics, Perth, Australia, pp. 207-218.

Williams, M.P.A., Murphy, S.D., MacNamara, L. and Khoshniaz, N. (2006) The Miduk Copper Project: Down-Valley Discharge of Paste Thickened Tailings, Design and Early Operating Experience, In Proceedings Ninth International Seminar on Paste and Thickened Tailings, Australian Centre for Geomechanics, Perth, Australia, pp. 117-130.

Williams, M.P.A., Seddon, K.D. and Fitton, T.G. (2008) Surface Disposal of Paste and Thickened Tailings - A Brief History and Current Confronting Issues, In Proceedings Eleventh International Seminar on Paste and Thickened Tailings, Australian Centre for Geomechanics, Perth, Australia, pp. 143-164. 
